\title{
Evidence of presynaptic and postsynaptic action of local anesthetics in rats $^{1}$
}

\author{
Angélica de Fátima de Assunção Braga ${ }^{I}$, Vanessa Henriques Carvalho"I, Franklin Sarmento da Silva Braga ${ }^{\text {III }}$, Gloria Maria \\ Braga Potério ${ }^{\mathrm{III}}$, Filipe Nadir Caparica Santos ${ }^{\mathrm{IV}}$ \\ ${ }^{I}$ Associate Professor, Department of Anesthesiology, Campinas State University (UNICAMP), Campinas-SP, Brazil. Intellectual, scientific, content and \\ design of the study; acquisition and interpretation of data; technical procedures; manuscript writing; critical revision.

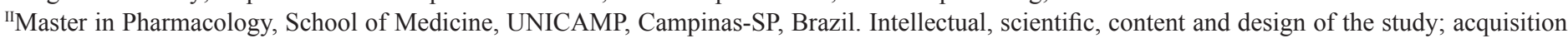 \\ and interpretation of data; technical procedures; manuscript writing; critical revision. \\ IIIAssistant Professor, Department of Anesthesiology, School of Medicine, UNICAMP, Campinas-SP, Brazil. Critical revision. \\ ${ }^{\text {IV }}$ Resident, Department of Anesthesiology, School of Medicine, UNICAMP, Campinas-SP, Brazil. Acquisition and interpretation of data.
}

\section{ABSTRACT}

PURPOSE: To assess the probable actions of ropivacaine, 50\% enantiomeric excess bupivacaine mixture (S75-R25) and levobupivacaine on neuromuscular transmission in vitro.

METHODS: Thirty rats were distributed into groups $(n=5)$ according to the drug used: ropivacaine, bupivacaine (S75-R25) and levobupivacaine. The concentration used for the three local anesthetics (LA) was $5 \mu \mathrm{g} \cdot \mathrm{mL} .{ }^{-1}$ The following parameters were evaluated: 1) LA effects on membrane potential (MP) and miniature end plate potential (MEPP). A chick biventer cervicis preparation was also used to evaluate LA effects on the contracture response to acetylcholine.

RESULTS: LA did not alter MP values and decreased the frequency and amplitude of MEPP. In a chick biventer cervicis preparation, bupivacaine (S75-R25) and levobupivacaine decreased the contracture response to acetylcholine with statistical significance, in comparison to ropivacaine.

CONCLUSIONS: In the concentrations used, levobupivacaine and bupivacaine (S75-R25) exhibited presynaptic and postsynaptic actions evidenced by alterations in miniature end plate potentials and contracture response to acetylcholine. Ropivacaine only had a presynaptic action.

Key words: Anesthetics, Local. Bupivacaine. Rats. 


\section{Introduction}

The mechanism of action of local anesthetics and their effects on synaptic transmission have not yet been fully elucidated. Furthermore, the effects of local anesthetics on the electrophysiological properties of the nerve cell body have also not been investigated in detail. Some authors have studied the iontophoretic effects of procaine on spinal motoneurons in cats submitted to orthodromic stimuli, and observed suppression of neuronal spike potential without alteration in excitatory postsynaptic potential and membrane resistance ${ }^{1}$. Other authors, using the dorsal root ganglion isolated from frog spinal cords, confirmed the depressant action of procaine in the generation of spike potential to direct stimulation of ganglion cells ${ }^{2}$. Tabatabai et $a l .{ }^{3}$ studied the effects of lidocaine and racemic bupivacaine on the presynaptic and postsynaptic components of synaptic transmission of the rat sympathetic ganglion and observed blockade in various stages of synaptic transmission. The effects of these drugs on membrane potentials and miniature end plate potentials were studied in rats and interference at some phase of neuromuscular transmission was described ${ }^{4-5}$.

The aim of this study was to evaluate the probable mechanisms of action of ropivacaine, 50\% enantiomeric excess bupivacaine S75-R25 mixture and levobupivacaine on neuromuscular transmission in experimental models.

\section{Methods}

This is an in vitro experimental study. The procedures used are in compliance with the ethical principles for animal experimentation, adopted by the Brazilian College of Animal Experimentation (BCAE) and were approved by the Ethics Committee for Animal Experimentation of the Institute of Biology of the State University of Campinas (protocol n ${ }^{\circ} 2346-1$ ).

To evaluate the effects of ropivacaine, $50 \%$ enantiomeric excess bupivacaine mixture and levobupivacaine on miniature end plate potentials and membrane potentials, a phrenic nerverat diaphragm preparation was used, according to methodology proposed by Bulbring ${ }^{6}$.

Thirty male Wistar rats (weight range: 180 - 250g) were used. Animals were anesthetized with urethane $\left(1.2 \mathrm{mg} \cdot \mathrm{kg}^{-1}\right.$, by intraperitonial injection), exsanguinated by severance of major blood vessels in the neck to facilitate the identification and removal of the left hemidiaphragm and portion of the corresponding phrenic nerve. The preparations were fixed in a vat containing 40 $\mathrm{mL}$ of Tyrode nutrient solution, constantly aerated with carbogen $\left(95 \% \mathrm{O}_{2}+5 \% \mathrm{CO}_{2}\right)$ and maintained at $37^{\circ} \mathrm{C}$. To evaluate local anesthetic effects on miniature end plate potentials and membrane potentials, the following groups were formed, according to the local anesthetic added to the preparation: Group I - ropivacaine; Group II - 50\% enantiomeric excess bupivacaine mixture; Group III - levobupivacaine. In all groups, local anesthetic concentration was $5.0 \mu \mathrm{g} . \mathrm{mL} .^{-1}$

To evaluate postsynaptic events of local anesthetics, a chick biventer cervicis preparation was used, mounted according to methodology described by Ginsborg and Warriner. ${ }^{7}$ Twelve chicks aged four to eight days, weighing from 40 to $80 \mathrm{~g}$, anesthetized with halothane by inhalation, followed by the removal of the biventer cervicis muscle, which was suspended in a $5 \mathrm{ml}$-tub containing Krebs nutrient solution. The preparation was aerated with carbogen and temperature was maintained at $37^{\circ} \mathrm{C}$. Experiments were performed $(n=4)$ for the detection of the acetylcholine curve $\left(5 \mathrm{~g} \cdot \mathrm{mL}^{-1}\right)$ before and 30 minutes after the addition of each local anesthetic: ropivacaine, $50 \%$ enantiomeric excess bupivacaine mixture and levobupivacaine, in the same concentration used in rat experiments $\left(5 \mu \mathrm{g} \cdot \mathrm{mL}^{-1}\right)$. Indirect stimulation of skeletal muscles was performed with supramaximal pulses (duration:0.2 $\mathrm{ms}$; frequency:0.1Hz). Responses to acetylcholine were recorded by a Gould RS 3400 chart recorder, before and 30 minutes after the addition of ropivacaine, $50 \%$ enantiomeric excess bupivacaine mixture and levobupivacaine.

Local anesthetic effects were evaluated on: 1) membrane potentials (MP) and miniature end plate potentials (MEPP); 2) contracture response to acetylcholine.

\section{Statistical analysis}

Results were expressed as means and standard deviations. For analysis of membrane potential of muscle fibers and contracture response to acetylcholine, Wilcoxon's test and Student's t-test for paired samples were used. A significance level of 5\% was adopted $(\mathrm{p}<0.05)$. The power of the test was calculated, obtaining $\mathrm{b}>$ $20 \%$ (power $>80 \%$ ).

\section{Results}

Ropivacaine, 50\% enantiomeric excess bupivacaine mixture and levobupivacaine in the concentrations studied, caused no significant alterations in membrane potentials. The effects of local anesthetics on miniature end plate potentials (MEPP) are initially characterized by a decrease in frequency and amplitude, observed 30 minutes after drug addition, followed by blockade in 
60 minutes.

In the chick biventer cervicis preparation, the percentages of decrease in the contracture response to acetylcholine, caused by the local anesthetics ropivacaine, 50\% enantiomeric excess bupivacaine mixture and levobupivacaine in the concentration studied $\left(5 \mathrm{mg} . \mathrm{mL}^{-1}\right)$ were $16.07 \% \pm 6.01 ; 33.12 \% \pm 11.51$ and $19.35 \% \pm 3.67$, respectively. This reduction was significant with $50 \%$ enantiomeric excess bupivacaine and levobupivacaine $(\mathrm{p}=0.01)$, in comparison to ropivacaine $(\mathrm{p}=0.12)$.

\section{Discussion}

Local anesthetics are a group of drugs that are widely used by different routes of administration, such as topical, subcutaneous infiltration, blockade of peripheral nerves and neuraxial anesthesia (spinal and epidural), in the prevention and relief of acute and chronic pain ${ }^{8-9}$. Because LA are amphiphilic molecules, they have high affinity for excitable cell membranes, inactivating voltage-gated sodium channels, and thus preventing the influx of ions necessary for membrane depolarization. It is believed that a decrease in membrane permeability to sodium ions occurs by two mechanisms: general alterations in membrane fluidity with conformational changes in protein-voltage-gatedsodium channel and/or by the specific interaction between local anesthetics and sodium channels ${ }^{10-12}$. On the other hand, a direct correlation between hydrophobicity and anesthetic potency indicates that nonspecific partition of a large quantity of local anesthetic in the lipid bilayer is important to facilitate access of the molecule to voltage-gated sodium binding sites ${ }^{13-14}$.

The enantiomeric bupivacaine mixture, ropivacaine, mepivacaine, racemic bupivacaine and levobupivacaine, commonly contain a chiral center in the piperidinic ring, providing optic isomers with $\mathrm{S}(-)$ and $\mathrm{R}(+)$ configurations, a stereoisometry that may also contribute to cell membrane fluidity ${ }^{12}$.

Theoretically, these agents may interfere in some phase involved in neuromuscular transmission. Local anesthetics selectively depress motor fiber conduction and reduce the release of acetylcholine during nerve stimulation by presynaptic action ${ }^{15-17}$. These drugs may bind to different specific acetylcholine sites, resulting in desensitization of these receptors by postsynaptic action. Furthermore, they may temporarily occlude nicotinic receptor channels ${ }^{18-20}$.

There is no evidence that LAs inhibit the synthesis of acetylcholine, but in low concentrations these agents interfere with miniature end plate potential. Thus, impairment in quantal release of acetylcholine and alterations in miniature end plate potential may manifest a presynaptic action. To evaluate local anesthetic action on presynaptic and postsynaptic sites, electrophysiological studies have been conducted. These experiments detect the spontaneous release of one quantum of acetylcholine and may investigate the influence of drugs used in the presynaptic region, due to its interference in the processes of mediator production or release. The postjunctional effect may be attributed to interference with the receptor occupied by the transmitter and the reduced sensitivity of the postjunctional membrane to acetylcholine 16-17,19-20. $^{1}$

In electrophysiological studies, similarly to other studies $^{4-5,22}$, we observed that local anesthetics did not produce alterations in the membrane potential of muscle fibers in the concentration employed, and potential is maintained within normal limits. According to descriptions by others authors ${ }^{21}$ it can be inferred that these drugs do not possess a depolarizing action on the muscle fiber. Their mechanism of action on the neuromuscular junction is not related to stabilizing activity of the muscle membrane. However, local anesthetics prevent the conduction of propagated action potentials, without affecting membrane potential.

The small amount of acetylcholine, ineffective to trigger an action potential, is continuously and spontaneously released and does not require electrical neural stimulation. This release is responsible for small amplitude potentials, corresponding to one hundredth the amplitude of the end-plate potential produced, named plate minipotential or miniature end plate potentials. The function of miniature end plate potential is unknown, but seems to be related to the maintenance of muscle trophism ${ }^{22}$. The study of MEPPs is important to investigate the presynaptic effects of the drugs used, due to its interference in mediator release ${ }^{22}$. In contrast to previous reports on lidocaine ${ }^{4-5,21}$, describing that it initially increases MEPP frequency, the local anesthetics used in the study caused a progressive decrease both in the frequency and amplitude of these potentials until complete blockade.

In the postsynaptic membrane, local anesthetics are capable of binding to specific areas of nicotinic receptors, different from specific areas of acetylcholine, promoting desensitization of these receptors ${ }^{18,23}$.

LA effects were also evaluated in the chick biventer cervicis preparation. Due to the high density of nicotinic cholinergic receptors present in bird muscles, the response to acetylcholine permits us to evaluate the affinity of these drugs to these receptors in the postsynaptic region. The results observed in this preparation indicate that different local anesthetics in the concentrations used, reduced the contracture response induced by acetylcholine, and are similar to those previously described by 
Braga et al. ${ }^{5}$. These authors found a significant decrease in the response to acetylcholine in preparations exposed to lidocaine and enantiomeric excess bupivacaine mixture.

\section{Conclusions}

Theresults suggestapresynaptic action, withmodifications in quantal release of acetylcholine and a postsynaptic action in nicotinic receptors, preventing or decreasing neurotransmitter action, and not an effect on muscle fibers. Therefore, there seems to be a curaremimetic action, with a probable action on the neuromuscular junction, particularly the motor nerve ending.

\section{References}

1. Curtis DR, Phillis JW. The action of procaine and atropine on spinal neurons. J Physiol. 1960;153:17-34.

2. Aceves J, Machne X. The action of calcium and of local anesthetics on nerve cells, and their interaction during excitation. J Pharmacol Exp Ther. 1963;140:138-48.

3. Tabatabai M, Booth AM. Mechanism of action of local anesthetics on synaptic transmission in the rat. Anesth Analg. 1990;71(2):14957.

4. Loyola YC, Braga Ade F, Potério GM, Sousa SR, Fernandes SC, Braga FS. Influence of lidocaine on the neuromuscular block produced by rocuronium: study in rat phrenic-diaphragmatic nerve preparation. Rev Bras Anestesiol. 2006;56(2):147-56.

5. Braga Ade F, Carvalho VH, Braga FS, Rodrigues-Simioni L, Loyola YC, Potério GB. Influence of local anesthetics on the neuromuscular blockade produced by rocuronium: effects of lidocaine and $50 \%$ enantiomeric excess bupivacaine on the neuromuscular junction. Rev Bras Anestesiol. 2009;59(6):725-34.

6. Bulbring E. Observation on the isolated phrenic nerve-diaphragm preparation of the rat. Br J Pharmacol. 1946;1:38-61.

7. Ginsborg BL, Warriner J. The isolated chick biventer cervicis nervemuscle preparation. Br J Pharmacol Chemother. 1960;15:410-1.

8. Covino BG. Pharmacology of local anaesthetic agents. Br J Anaesth. 1986;58(7):701-16.

9. Yanagidate F, Strichartz GR. Bupivacaine inhibits activation of neuronal spinal extracellular receptor-activated kinase through selective effects on ionotropic receptors. Anesthesiology. 2006;104(4):805-14.

10. Ragsdale DS, Avoli M. Sodium channels as molecular targets for antiepileptic drugs. Brain Res Brain Res Rev. 1998;26(1):16-28.

11. Li HL, Galue A, Meadows L, Ragsdale DS. A molecular basis for the different local anesthetic affinities of resting versus open and inactivated states of the sodium channel. Mol Pharmacol. 1999;55(1):134-41.

12. Mizogami M, Tsuchiya H, Harada J. Membrane effects of ropivacaine compared with those of bupivacaine and mepivacaine. Fundam Clin Pharmacol. 2002;16(4):325-30.

13. dePaula E, Schreier S. Molecular and physicochemical aspects of local anesthetic-membrane interaction. Braz J Med Biol Res. 1996;29(7):877-94.

14. Schreier S, Malheiros SV, de Paula E. Surface active drugs: selfassociation and interaction with membranes and surfactants. Physicochemical and biological aspects. Biochim Biophys Acta. 2000;1508(1-2):210-34.
15. Hirst GD, Wood DR. On the neuromuscular paralysis produced by procaine. Br J Pharmacol. 1971;41(1):94-104.

16. Matthews EK, Quilliam JP. Effects of central depressant drugs upon acetylcholine release. Br J Pharmacol Chemother. 1964;22:415-40.

17. Usubiaga JE, Standaert FJ. The effects of local anesthetics on motor nerve terminals. Pharmacol Exp Ther. 1968;159(2):353-61.

18. Sine SM, Taylor P. Local anesthetics and histrionicotoxin are allosteric inhibitors of the acetylcholine receptor. Studies of clonal muscle cells. J Biol Chem. 1982;257(14):8106-4.

19. Neher E, Steinbach JH. Local anaesthetics transiently block currents through single acetylcholine-receptor channels. J Physiol. 1978;277:153-76.

20. Ruff RL. The kinetics of local anesthetic blockade of end-plate channels. Biophys J. 1982;37(3):625-31.

21. Carvalho VH, Braga Ade F, Braga FS, Loyola YC, de Araújo $\mathrm{DR}$, Mantovani $\mathrm{M}$. The influence of lidocaine and racemic bupivacaine on neuromuscular blockade produced by rocuronium. A study in rat phrenic nerve-diaphragm preparation. Acta Cir Bras. 2009;24(3):211-5.

22. Fatt P, Katz B. Spontaneous subthreshold activity at motor nerve endings. J Physiol. 1952;117:109-28.

23. Martins TD, Loyola YC, Braga Ade F. Influence of procainamide on the neuromuscular blockade caused by rocuronium and investigation on the mechanism of action of procainamide on the neuromuscular junction. Rev Bras Anestesiol. 2007;57(1):74-82.

\section{Correspondence:}

Angélica de Fátima de Assunção Braga

Rua Dr. José Bonifácio Coutinho Nogueira, 225/61 Torre D

13091-611 Campinas - SP Brasil

Tel.: (55 19)3521-9560

franklinbraga@terra.com.br

Received: July 23, 2013

Review: Sept 20, 2013

Accepted: Oct 22, 2013

Conflict of interest: none

Financial source: none

${ }^{1}$ Research performed at Department of Anesthesiology and Pharmacology, School of Medicine, Campinas State University (UNICAMP), CampinasSP, Brazil. 